\title{
Studies on the necessity of the transaction of air pollution emission in 'Dianzhong' economic zone
}

\author{
Wen Gao
}

Oxbridge college, Kunming university of science and technology,panpanbear@hotmail.com

Key words: "Dianzhong" economic zone The transaction of air pollution emission

Abstract. "Dianzhong” economic zone is consist on Kunming city, Qujin city, Yuxi city and Chuxiong City. The position of the economic zone is central of Yunnan province. In "Shisanwu"plan, the "Dianzhong" economic zone be considered the cord area, the power and the leader of the economic development of Yunnan province. But in this zone, there are more than $60 \%$ industries firms. The air pollutions effect the living conditions and human health. Only charge the sewage by government seem to do nothing. We should establish the transaction of air pollution emission to control the total output about air pollution reference from America and Europe. The article will describe what is the transaction of air pollution emission, and the necessary about why should establish it.

In 2008, the Yunnan province presented the idea of "Dianzhong" economic zone. Marche of 2011, < To promote the integration of development cooperation framework agreement $>$ are signed by Kunming city, Yuxi city, Chuxiong city and Qujin city. Then, the “Diangzhong” economic zone was born. The economic zone include Kunming city, Yuxi city, Chuxiong city and Qujin city, even come to Mengzi, Jianshui, Kaiyuan, Milei, Luxi and Shiping. The land area of 114600 square kilometers, accounting for the total Yunan province 29\% land area. Until 2012, the population of the "Dianzhong" economic zone reach $44.06 \%$ of whole Yunnan province. The GDP account $65.56 \%$ of total. The local fiscal revenue is $66.1 \%$. the retail sales of social consumer is $67.54 \%$. The investment in fixed assets is $56.19 \%$. the import and export og goods and services is $80.49 \%$. the add value of industry is $8.63 \% .1$ in addition, there are metallurgical processing area, petrochemical area, new coal area. According 2015 statement, the adding value of industry run up to 8 !\% of whole province. Also, the emission of air pollution account for more that $50 \%$. It contained Sulfur dioxide, nitrogen oxides, particulate matter and volatile organic compound and so on 2 . Building the transaction of air pollution emission in economic zone seem to improve the process of environment protection an optimize resources.

\section{The transactions of air pollutions emission}

The transactions of air pollutions of emission based on the total emissions of pollutants in the premise of index is determined, the use of market mechanisms to establish legal pollutant discharge right. The right is allow the sewage. The right can be considered as commodity, and commodity can be sold. As the result, the total amount of pollutants are fixed, and pollutant emissions seem to reduced. Finally, the transactions of air pollutions emission will protect the environment.

The transactions of air pollutions of emission is not a new staff. It came form America. In 1968,

\footnotetext{
1 Jinshu Ma, Improve the development in the 'Dianzhong' economic zone, Yunnan daily, September 12,2012

2 Junli Zhang, The situations and the plan of environment in the 'Dianzhong' economic zone, Environment and science, vol.23, 2013
} 
the economist Davis propose the concept of the transactions of air pollutions emission in book $<$ pollutions, wealthy and price $>$. After 22 years, the American government put this concept into The Clean Air Act. It has played a significant role in reducing SO2 emissions in the United States. Following America, the euro and Australia also using the transactions of air pollution emission to handle the environment problems. In international financial market, the carbon emission trading is one important derivative financial tool. Every year has a huge transactions and create several trillion dollars.

\section{The necessity of the transaction of air pollution emission in 'Dianzhong' economic zone}

The 'Dianzhong' economic zone include Kunming city, Yuxi city, Chuxiong city and Qujin city, even come to Mengzi, Jianshui, Kaiyuan, Milei, Luxi and Shiping. The economic zone close to north of Sichuan and the north bay, connecting the Pacific and Indian ocean. The terrain is relatively flat, on the 2 / 3 is dam area. Relatively terrain is conducive to the proliferation of atmospheric pollutants. The emissions of pollutants in a certain place in the economic zone can be spread to anywhere in this areas through rivers, air, etc.. Especially SO2 and other air pollutants, it has a wide range of impact. The air pollutants discharged from any area in the 'Dianzhong' Economic Zone may spread to the whole Yunnan Province, and affect the air condition of the region. For the long time,due to the lack of an integrated management system, the government of the district government pursues the growth of GDP and the existence of local protectionism. At he beginning of 2015, 'the Kunming blue', ' the Yunnan blue ' and 'the Dali blue' are disappeared for few days. The gray sky came to Yunnan. If we want to protect 'the Yunnan blue', it should establish the transactions of air pollution emissions in 'Dianzhong' economic zone. The emission seem to control the total pollutants in economic zone, and after few years, slowly decreased the air pollutions. According to the emission reduction targets of air pollutants in national and economic zones, the total amount of air pollutants in the economic zone is set. On this basis, discharge permit issued to the enterprise, allowing the transaction of surplus emission rights. As the result, we can control the emission of air pollutants in the economic area and improve the effect of regional environmental protection.

From the effect of emission rights part, the greater the scope of participation in emissions trading, the area within the scope of the better allocation of resources optimization. The more pollution sources involved, the more opportunities for the right to buy or sell, the greater the necessity and possibility of emission trading. In August 2008, the Kunming environment and energy exchange, which was established. It was the first discharge exchange of pollutants in the southwest of China. The main object of exchange is the emission and emission rights. Emission rights include, such as, chemical oxygen demand in the process of governance in Dianchi, sulfur dioxide desulfurization in the thermal power industry, etc.. Mainly refers to the emissions is carbon dioxide emissions. And emissions and emission reduction including the mandatory and voluntary emission reduction. The former refers to the "Kyoto Protocol" according to the provisions of the developed countries to the developing countries to buy emission rights. Because the transaction involved a small number of enterprises, businesses cut capacity of air pollutions is limited. As the result, the trading emission market size is too small, or even frequent in emissions market has zero transaction. Therefore, it is necessary to expand the scope of the existing emissions trading market of air pollutants, and to implement the integration of air pollutant emission trading in the 'Dianzhong' Economic zone.

According to the statistics of Yunnan Province Environmental Bulletin of 2012, based on the air quality index (AQI) evaluation, with sulfur dioxide, nitrogen dioxide and as the annual average 
concentration of four particle value evaluation3. The 'Dianzhong' economic zone was in second level. But this year the highest concentration of nitrogen dioxide $0.033 \mathrm{mg}$ per cubic meter, appeared in Kunming city. The overall rate of air in 2012 was excellent; 100\% in Yuxi city, Kunming city, Chuxiong city and Qujing city were 99.7\%. come to 2013, 2the whole year AQI reached two class standard limit, the inhalable particles (PM10) more than the second level standard 0.25 times, inhalable particles (PM2.5) is 0.53 times of the second level standard. By 2014, emissions of air pollutants increased, three of Cities in 'Dianzhong' Economic Zone decreased the rate of air quality, Kunming air rate was 97\%, Qujing was 97.3\%, Yuxi was 98.1\%, and the maximum value of the annual sulfur dioxide and carbon monoxide appeared in Yuxi, and the maximum value of the annual PM10 and PM2.5 were found in Kunming. 2015, 16 cities in Yunnan province appeared heavy pollution for 1 days, moderate pollution for 7 days, light pollution of air pollution for 150 days. Kunming and Yuxi air quality rate was $97.8 \%$ and $97 \%$, compared with the previous year increased by $0.8 \%$ and $1.4 \%$. The highest value of nitrogen dioxide in Kunming. 16 in Yunnan city in the rate of air quality ranked sixth in Chuxiong, Yuxi eighth, Qujing eleventh, Kunming ranks thirteenth.

The sustainable economic development in the 'Dianzong' Economic Zone, we must increase the intensity of air pollution control. Except, taken off structure of "five small" enterprises, flue gas desulfurization, industrial upgrading, sewage charges etc. we also need to adopt innovative environmental management policy, governance of air pollution in the market. And establish the transactions of air pollutions of emission in the economic zone.

At present, in Yunnan Province, the main measures to control the emissions of air pollutants is the charging system. The pollutant discharge system refers to the discharge of pollutants to the environment or the discharge of pollutants exceeding the state standards, according to the type, quantity and concentration of pollutants, and the relevant laws and regulations. According to the principle of "polluter pays" and "who pollutes who governs", the system of the sewage charges will internalize the external cost of the enterprise through the form of the pollutant charge. This policy has a certain effectively promoted the development of pollution control and new technologies, to reduced emissions of air pollutants. It has played a certain effect. But the charging system is a typical control mode command control, the enterprise just passively accept the government regulations, the lack of enthusiasm for the initiative to reduce emissions of pollutants. For example, In 2016, at Yunnan Province Environmental Protection Bureau website publicity in 2015 still state-controlled enterprises unpaid sewage charges list (two Qujing city enterprises in arrears.) The emissions trading system is a market-based environmental management tools that can mobilize the enterprise to control pollution, and reduce the enthusiasm of pollutant emissions. Polluters in the emissions trading market, consider their own interests, independently determine the degree of pollution control, and then buy or sell emission rights. In the process, the optimal allocation of resources spontaneously. This is because the difference in the cost of pollution treatment of different enterprises is very large. When the emission rights can be paid transfer, those companies with low governance costs. And then, it can as far as possible to control pollution. Finally, transfer the right to profit. The high cost of governance of the enterprise, as long as the cost of governance more than the price of emission rights, the businesses can buy emissions rights through the legal discharge of pollutants. Thus, lack of emission trading can make up for the charging system. The emission rights seem to improve the enthusiasm of enterprises and the regional air pollution control effect.

3 The report of the situations of environment In Yunnan, Yunnan environment protection department, 2015. 


\section{Summary}

Based on the above analysis, we should make a conclusion that it is necessary to establish the regional air pollutant emissions trading system in the 'Dianzhong' Economic Zone ( Kunming, Yuxi, Chuxiong and Qujing). Through the establishment of regional integration of trade to protect environmental resources, maintain the sustainable development of the region and make up for the deficiencies of the existing sewage charges system.

\section{Reference:}

[1] The report of the situations of environment In Yunnan, Yunnan environment protection department, 2015.

[2] The report of the situations of environment In Yunnan, Yunnan environment protection department, 2014.

[3] The report of the situations of environment In Yunnan, Yunnan environment protection department, 2013.

[4] The report of the situations of environment In Yunnan, Yunnan environment protection department, 2012.

[5] Jinshu Ma, Improve the development in the 'Dianzhong' economic zone, Yunnan daily, September 12,2012.

[6] Junli Zhang, The situations and the plan of environment in the 'Dianzhong' economic zone, Environment and science, vol.23, 2013.

[7] The plan of the development about the 'Dianzhong' economic zone(2014-2024), General Office of Yunnan provincial government, 2014.

[8] Minde Leng, improve the development between Kunming and Yuxi based on 'Dianzhong' economic zone, Yuxi daily, July 2011.

[9] Dele Niu, studies on the economic development in 'Dianzhong' economic zone, the journal of northwest normal university, vol. 4, 2013. 